\title{
Correction to: Effects of Allium cepa-mediated zinc oxide nanoparticles on male reproductive tissue and sperm abnormalities of albino mice (Mus musculus)
}

\author{
Asia Iqbal ${ }^{1} \cdot$ Muhammad Zakir $^{1} \cdot{\text { Muhammad Muddassir } \text { Ali }^{2} \text { (D) Shagufta Irshad }}^{3} \cdot$ Arshad Javid $^{1}$. \\ Muhammad Khan ${ }^{4}$. Chaman $\mathrm{Ara}^{4} \cdot$ Asmatullah $^{4}$
}

Published online: 7 April 2021

๑) King Abdulaziz City for Science and Technology 2021

\section{Correction to: Applied Nanoscience (2021) 11:807-815 https://doi.org/10.1007/s13204-020-01633-2}

In the online published article, the co-authors (Muhammad khan and Asmatullah) affiliation has been published incorrectly. The correct affiliation is given below.

Muhammad khan4

Asmatullah4
4Department of zoology, University of the Punjab, Lahore, Pakistan

Publisher's Note Springer Nature remains neutral with regard to jurisdictional claims in published maps and institutional affiliations.

The original article can be found online at https://doi.org/10.1007/ s13204-020-01633-2.

Muhammad Muddassir Ali muddassir.ali@uvas.edu.pk

1 Department of Wildlife and Ecology, University of Veterinary and Animal Sciences, Lahore, Pakistan

2 Institute of Biochemistry and Biotechnology, University of Veterinary and Animal Sciences, Lahore, Pakistan

3 Department of Chemistry, Government Post Graduate College for Women, Gulberg, Lahore, Pakistan

4 Department of Zoology, University of the Punjab, Lahore, Pakistan 